\title{
Analysis of the Spatial Behaviour of Masonry Bridges Via Hierarchical FEM Modelling: the Devil's Bridge
}

\author{
I. Corbi, O. Corbi, F. Tropeano
}

\begin{abstract}
The contribution of the fill to the global behavior of masonry vaulted bridges may be primarily significant. Nevertheless, ordinary analyses conducted on masonry bridges usually consider only the main structural vaulted elements. The paper reports some results obtained through a numerical simulation developed on a FEM model of an ancient bridge, the Devil's bridge on Sele river at Barrizzo, in the Campania region. The study is aimed at showing how the fill may be contributing with a significant static action , changing the real carrying capacity of the bridge as regards applied loads. The study allows to highlight the spatial behavior of the single components and of the overall structure as well, in terms of stresses and deformed configurations under the self- weight and the accidental loads.
\end{abstract}

Keywords - FEM, Modelling, Masonry, Bridge, Vault, Fill.

\section{INTRODUCTION}

$\mathrm{T}_{\mathrm{h}}^{\mathrm{h}}$ he complex structure of ancient masonry bridges allow to highlight the relevance of studying a number of features [1]-[7], including the 3D behavior and the interaction effects between structural and non-structural components. In masonry constructions the No-Tension assumption is usually adopted for suitably treating the material non-linearity [8][32]. In the examined case, it appears very important to deepen the action exerted by the fill with regards to loads that are usually assumed to be sustained only by the vault.

I. Corbi is with the Department of Structural Engineering and Architecture of University of Naples "Federico II", Via Claudio 21, 80125 Napoli, ITALIA (corresponding author, phone: +39-081-7683726; e-mail: ileana.corbi@unina.it).

O. Corbi is with the Department of Structural Engineering and Architecture of University of Naples "Federico II", Via Claudio 21, 80125 Napoli, ITALIA (e-mail: ottavia.corbi@unina.it).

F. Tropeano is with the Department of Structural Engineering and Architecture of University of Naples "Federico II", Via Claudio 21, 80125

Napoli, ITALIA (e-mail: francescanicole@alice.it).
In the following, one reports some results from the numerical investigation developed on the Devil's bridge on the Sele river at Barrizzo in the Campania Region, which is characterized by one single vaulted span and is integrally composed of masonry blocks. The geometrical shape is sharply reproduced in the FEM modeling, both as regards the external appearance and the internal organization of the components. This also includes the reproduction in the model of: the shape and spatial orientation of the blocks; the presence of some inner lightning in the fill; the hierarchical organization of the structural and non-structural components in their spatial layout; the different masonry material and mechanical properties at different points in the structure.

\section{THE FEM MODELLING OF THE DEVIL's BRIDGE}

\section{II.1 Introduction to FEM analysis of Devil's bridge}

A FEM model has been developed for the Devil's bridge in Capaccio in order to analyze the overall behavior and to interpret the contribute of the fill on the global response of the structure. The fill that characterized this masonry vaulted bridge is made of stone blocks with some internal curved holes.

The adopted mesh has been studied in order to reproduce as much as possible the bricks' layout and general arrangement within every single component, that is the tympanum, the fill and the main vault. Moreover the materials and their mechanical properties are respected. In the model they are diversified according to the different structural and not structural components in order to obtain the response of the bridge as reliable as possible, in terms of stresses and deformed configurations. 


\section{2 The FEM model}

A number of analyses have been developed based on the selected mesh in order to study the global behavior of the structure. The analyses have been performed in both a $2 \mathrm{D}$ and $3 \mathrm{D}$ environment, and developed on the vaulted span or on the complete bridge. As mentioned in Sec. I, the specific selected mesh is able, in the single cases, to reproduce the real brick layout at any point of the construction. Moreover, based on this choice, the structure, when studied in its complete configuration, has been reproduced in its hierarchical organization; in this case, in the adopted mesh, one has sub-divided the structure in a number of substructures coinciding with the structural and non-structural components. These substructures are then reassembled through the introduction of the mutual constraints between the components in order to obtain the global response of the bridge, but they may be also studied separately.

The mesh is then able to give a quite reliable representation of the masonry tissue reproducing as much as possible the real brick arrangement, and, in case of complete structure, the overall hierarchical organization and reciprocal relationships of the single components.
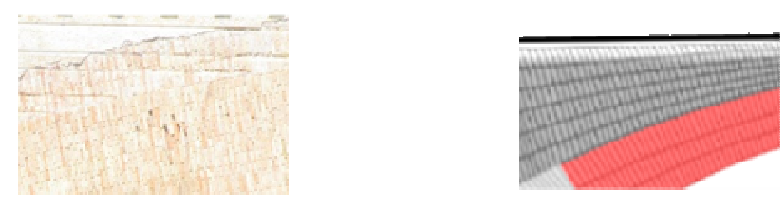

Figure 1: Detail of solid elements.

Solid elements are adopted in order to interpret the threedimensional stress state on any model of the bridge. The elements are given a prismatic shape in order to follow the real arrangement, with connecting joints. External constraints are introduced as well. In order to simulate the lateral soil constraint, the lateral joints are constrained by unilateral horizontal supports, that limit the translational motion in the horizontal direction.

\section{The Modelling OF DeVIL'S BRIDGE}

\section{III.1 The substructures}

The first analyses have concerned the main structural member, that is to say the vaulted span of the bridge. In subsequent analyses one has considered the complete structure including all its components. In this case one has considered a number of substructures in order to interpret the global behavior of the bridge and also the structural contribution of the fill onto the global response.
In order to emphasize this latter feature, analyses have been executed on both the two- dimensional and threedimensional system.

Moreover one has considered two cases, concerning the arrangement of the fill. In one case one has considered the real arrangement, which is characterized by internal curved holes; in the other case one has considered the fill without the curved holes.

The synthetic list of the main substructures identified in the mesh is reported in Table 1, where the substructures 2 and 3 are alternatively selected in the model. In Table 2 one reports the assemblies of substructures that are alternatively selected for studying the single vault, and the two mentioned cases.

Table 1: Substructures' identification.

\begin{tabular}{|l|}
\hline 1. Arcade \\
\hline 2. Vault \\
\hline 3. Fill without internal holes \\
\hline 4. Fill with internal holes \\
\hline 5. Tympanum \\
\hline
\end{tabular}

Table 2: Substructures' assemblies

\begin{tabular}{|l|}
\hline 1. Vault \\
\hline 2. Vault, tympanum and fill without lightening \\
\hline 3. Vault, tympanum and fill with lightening \\
\hline
\end{tabular}

The sub-structure of the vault in Fig. 2, is obtained by assembling the substructures of the arches, and re-proposing the same number of arches used in the real construction, both in the longitudinal and transversal planes .

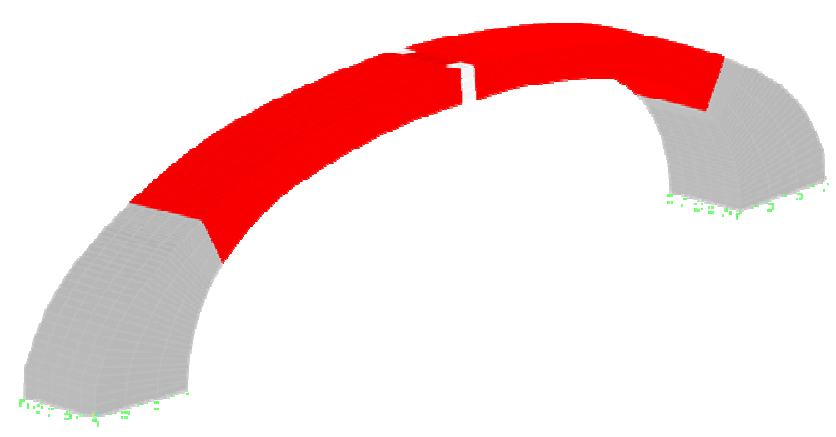

Figure 2: The vault substructure. 
In the transversal plane, the vault is characterized by five arches, suitably connected between each other, which are reproduced in their geometry and thickness in the model .

The assembly vault/tympanum/fill is modelled in two hypothesis:

- fill with internal curve holes

- fill without internal curve holes

The two cases are depicted in Fig. 3 and 4, where the frontal longitudinal views of the two models are reported. For the realization of the mesh, all sub- elements are considered both in the supporting components and in not supporting components.

They are modelled considering the real spatial orientation of the blocks. These are assembled into the sub-structures to proceed to their assembly for the complete modeling of the structure. In this way it was possible recognize the structural behavior and function executed by every component. Through the use of the specific mesh, the internal curved holes into the fill are also accounted for. In order to meet this requirement, in addition to the prismatic elements with eight nodes, also pyramidal elements with five nodes have been adopted.

The model is then built in such a way to view at the structure as divided in sub- structures, and to, subsequently, re-assemble those in order to get the global response of the bridge.

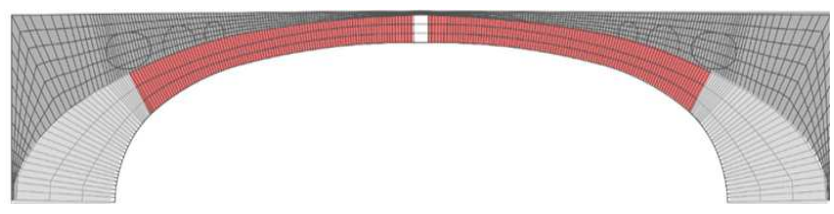

Figure 3: Model of the bridge with vault/tympanum/lightened fill assemblage.

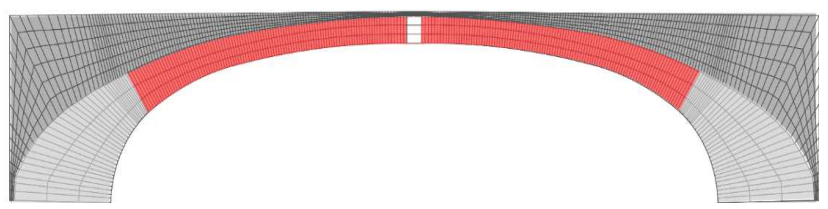

Figure 4: Model of the bridge with vault /tympanum/ un-lightened fill assemblage.

This type of modeling was first adopted for 2D analyses allowing to highlight the behavior of the structural and notstructural components in terms of deformed configurations and maximum and minimum principal stresses.

The response of the bridge is considered under the jointed action of its own weight and of the accidental loads as deducted by application of the Italian instructions NTC2008.
The loads were selected and suitably placed after a preliminary calculus realized for identifying the most dangerous load condition for the structure.

\section{III.2 Numerical investigation : $2 D$ results}

In the following one reports some of the results obtained after developing the 2D analysis, in terms of stresses and deformed configuration both for its own weight and the accidental loads. The first results concern the only substructure of the vault.

As concern the behavior of the vault under its own weight, as shown in the deformed configuration reported in Fig. 5, the maximum deflection is attained at the keystone, as expected. Here the minimum compression is attained as shown in Fig.6, where it attains an intensity higher than $-2,34 \cdot 10^{3} \mathrm{kN} / \mathrm{m}^{2}$, as it can be read from the relevant intensity scale to be amplified by the factor $10^{3}$.

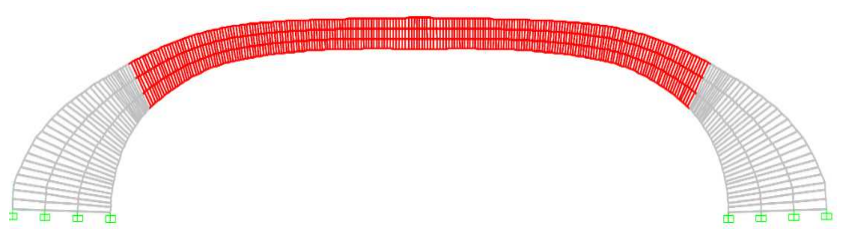

Figure 5: Deformed configuration of the main vault under the self-weight.

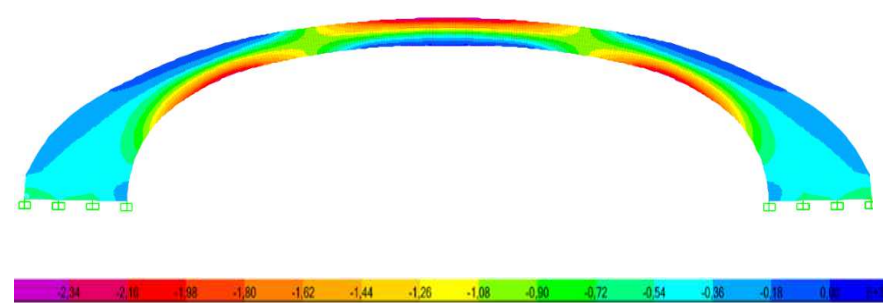

Figure 6: Minimum principal stresses in the main vault $\left(\mathrm{kNm}^{2}\right.$, values to be amplified by the factor $\left.10^{3}\right)$.

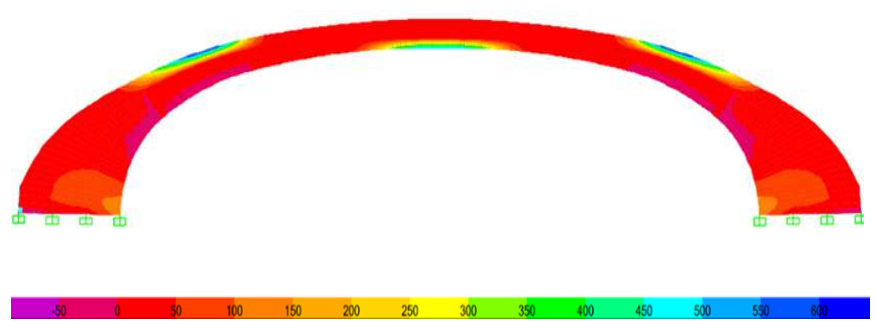

Figure 7: Maximum principal stresses in the main vault $\left(\mathrm{kN} / \mathrm{m}^{2}\right)$. 
As it can be observed by Fig.7 where the maximum principal stress intensities are reported, to be read in the related colour-intensity scale, the vault is practically compressed everywhere, with some tensions developed at the key-intrados and at the reins' extrados.

Further analyses have shown that the fill contribute to the static action, cooperating with the main vault. In Fig. 9 one shows the deformed configuration of the whole structure with the lightened fill, as in the real structure, under the self-weight of the structure. The maximum deflection is attained at the keystone, in the central section of the fill.

Comparing the above- mentioned system to the one with the un-lightened fill in Fig.10, one may immediately notice a decrease in the deformation caused by the absence of the inner holes in the fill. The maximum deflection attained at the keystone is smaller than the one attained in the lightened fill, confirming the cooperation of the fill to the overall static function.

As concern to the results about intensities of stresses in the lightened case in Fig.11, they appear of the same order of those obtained in the $2 \mathrm{D}$ system with fill without holes in Fig.12. However, a different distribution of stresses is shown caused by the presence of empties.

The results described in Fig.9-12 concern the response of the structure in the $2 \mathrm{D}$ environment as an effect of the application of the only self-weight, allowing to clearly emphasizing the influence relevant to the holes' presence in the stress spread in the inner of the bridge and its deformation.

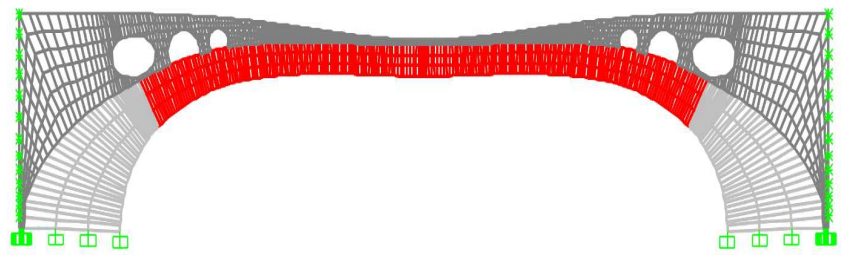

Figure 9: Deformed configuration of the 2D assembled system with inner holes.

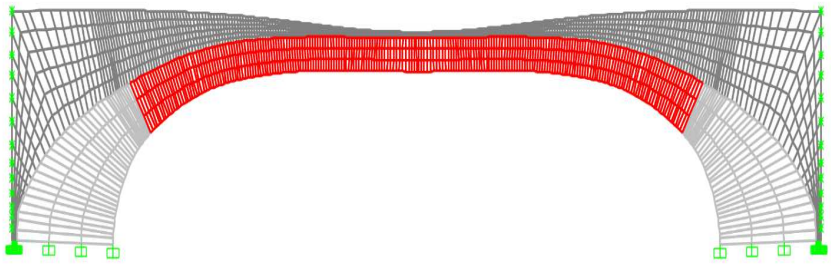

Figure 10: Deformed configuration of the 2D assembled system without inner holes.

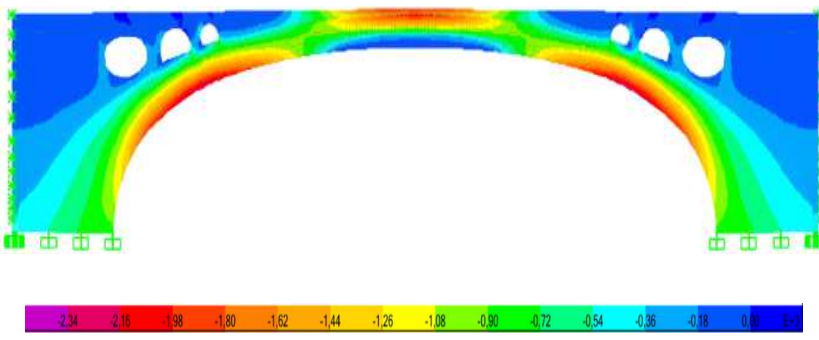

Figure 11: Spread of minimum principal stresses in the structure with inner holes $\left(\mathrm{kNm}^{2}\right.$, values to be amplified by the factor $\left.10^{3}\right)$.

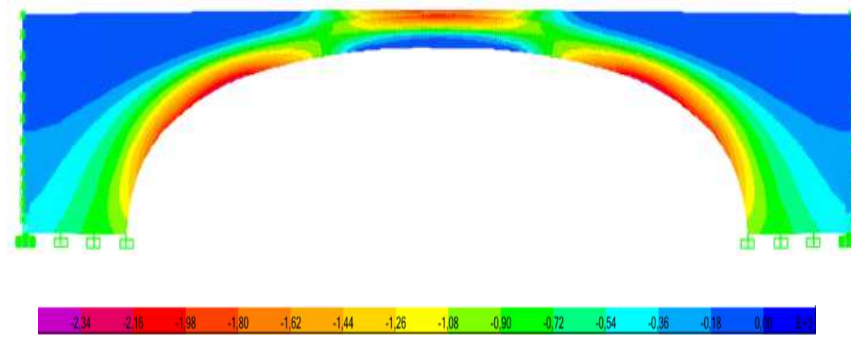

Figure 22: Spread of minimum principal stresses in the structure without inner holes.

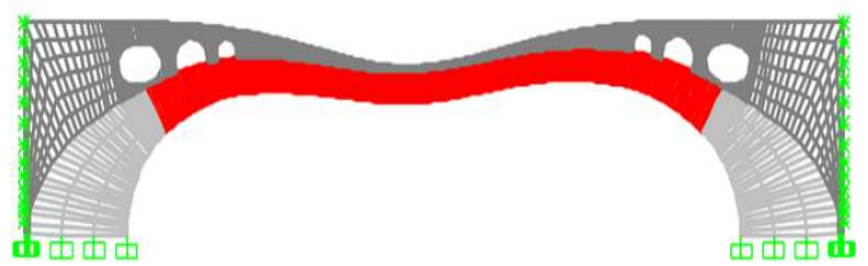

Figure 13: Deformed configuration of the 2D assembled system with holes under the coupled action of the self-weight and the accidental loads.

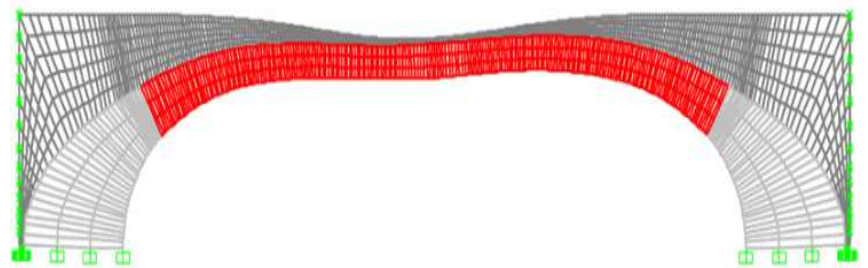

Figure 14: Deformed configuration of the $2 D$ assembled system without holes under the coupled action of the self-weight and accidental loads. 


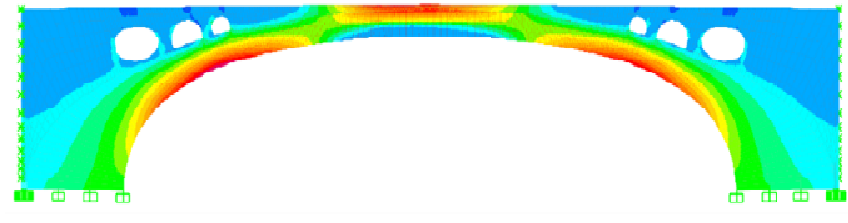

Figure 15: Spread of minimum principal stresses in the structure with inner holes under the coupled action of the self-weight and the accidental loads $\left(\mathrm{kN} \mathrm{m}^{2}\right.$, values to be amplified by the factor $\left.10^{3}\right)$.

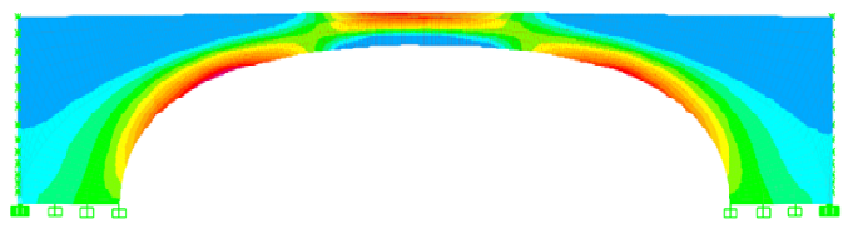

Figure 163: Spread of minimum principal stresses in the structure without inner holes, under the coupled action of the self-weight and the accidental loads $\left(\mathrm{kN} / \mathrm{m}^{2}\right.$, values to be amplified by the factor $\left.10^{3}\right)$.

\section{III.3 Numerical investigation: $3 D$ results}

In the following phase, $3 \mathrm{D}$ analyses have been performed by the suitable spatial re-assembling of all the bridge's components in its 7,00 m thickness, as shown in Fig.17 for some sub-structures. The analyses are repeated on the 3D model whose mesh is shown in Fig.18, under the structure own weight and the accidental loads, positioned according to the preliminary limit analysis.

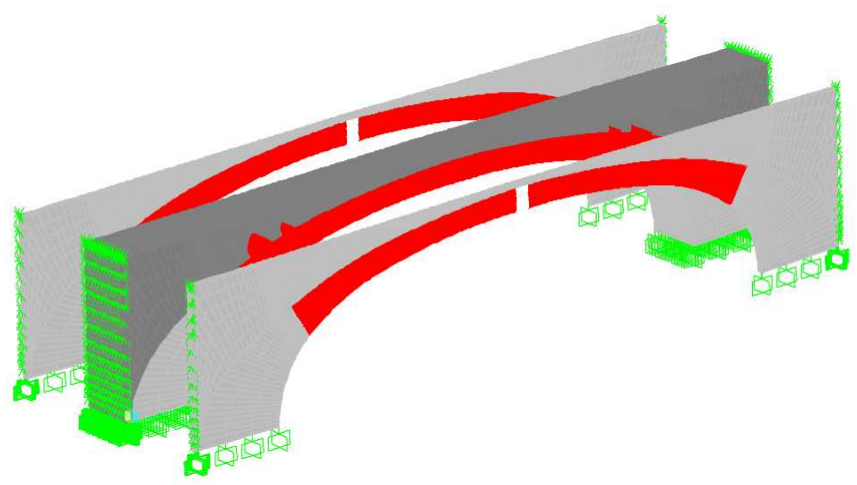

Figure 17: Spatial re-assembling of the bridge's sub-structures.
The elements in the mesh are given a prismatic or pyramidal shape according to their position, and arranged in way to follow the real spatial orientation of the stone blocks.

In the spatial model the loads are positioned according to their real spatial distribution as regards the self-weight, and on the first and second lane according to the instructions, as regards the accidental loads. The global effects on the structural response are then studied in terms of stresses and deformed configuration.

As an example one reports in Fig. 19 and 20 the deformed configurations under the jointed action of the fixed and variable loads for the un-lightened and lightened structure.

\section{CONCLUSIONS}

In conclusion, in the paper one has focused on the analysis of the 2D and 3D static response of an historical masonry bridge under fixed and variable loads. The effects of the contribution of the single structural components to the overall behaviour are emphasized by following the hierarchical reassemblage of the components that may be studied separately from each other or in conjunction with the other ones to highlight a number of features. This objective is pursued through the selection of a number of sub-structures that are able to reproduce the real operation of the construction. In particular the study case, concerning an ancient bridge on the Sele river, is characterized by a fill with some internal lightening obtained through the realization of some cavities with circular section. Numerical analyses are developed in the $2 \mathrm{D}$ and $3 \mathrm{D}$ environment on the model where the fill is sharply reproduced with its inner holes or it is considered without the inner lightning, and the observation of the spread of stresses and of the deformed configurations is done, highlighting the main features of the behaviour of the structure.

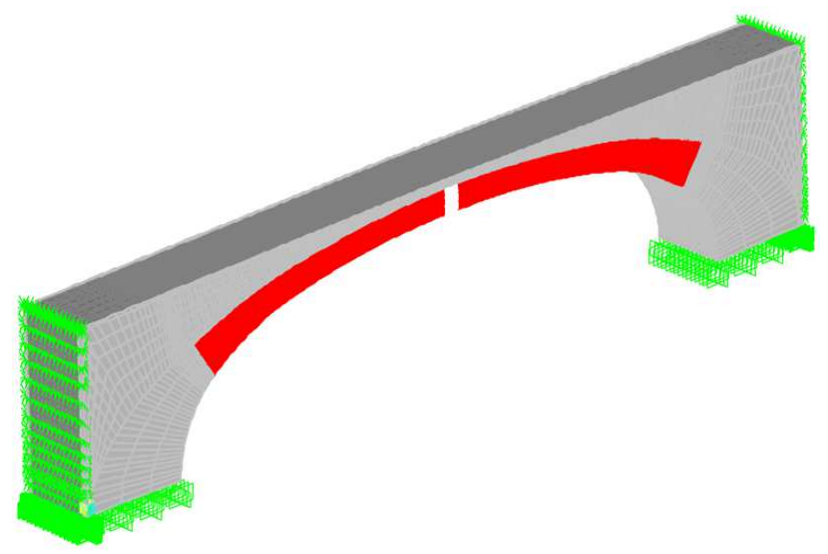

Figure 18: The FEM 3D model of the Devil's bridge. 


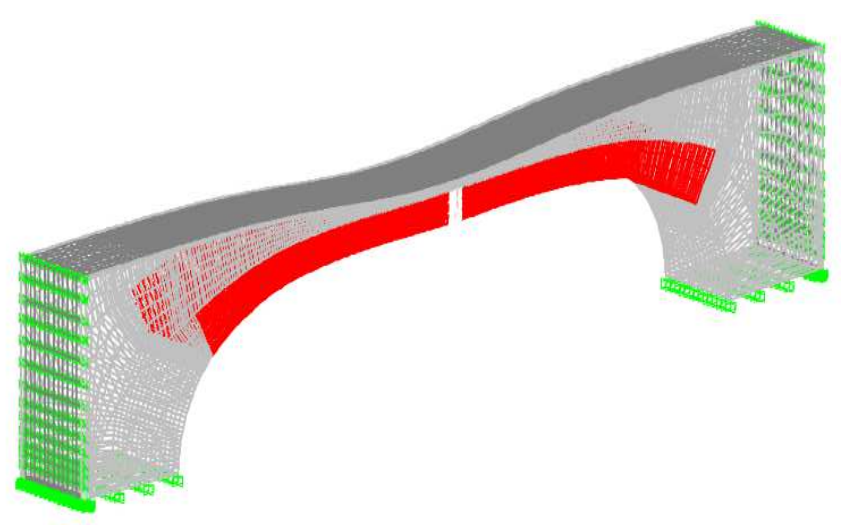

Figure 19: Deformed configuration of the 3D assembled system with internal holes under the coupled action of the self-weight and the accidental loads.

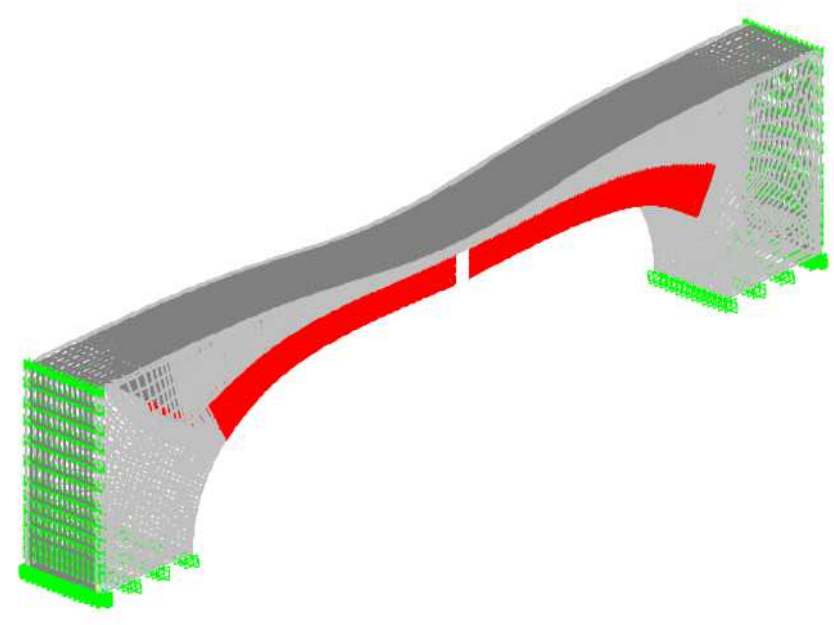

Figure 20: Deformed configuration of the $3 D$ assembled system without internal holes under the coupled action of the self-weight and the accidental loads.

\section{ACKNOWLEDGEMENT}

The authors acknowledge the financial contribution of the Dept. Civil Protection through the ReLuis pool (convention signed 27/12/2013).

\section{REFERENCES}

[1] Galliazzo, V.: I ponti Romani, vol.1-2, Treviso, Canova (1994).

[2] Galliazzo, V.: I ponti Romani, in II Congreso de las Obras Romanas, Tarragona, (2004).

[3] Meomartini, A.: I Monumenti e le opera d'arte della città di Benevento, pp. 261-290 (1889).

[4] Miccio, B., Potenza, U.: Gli Acquedotti di Napoli, A.M.A.N., Napoli, (1994).

[5] "Sulla via Appia da Roma a Brindisi: Le fotografie di Thomas Ashby 1891-1925", a cura di cura di Susanna Le Pera Buranelli e Rita Turchetti, Roma, ICCD pubblicazioni, (2003).
[6] Torre, C.: Ponti in Muratura. Dizionario Storico- Tecnologico, Firenze, Alinea Editrice (2003).

[7] "Instructions for the Assessment of the Structural Safety of road existing masonry bridges", national coordinators A. Baratta and O. Corbi, National Council of Researches, CNR-DT 213 (2015).

[8] Baratta, A., Corbi, O.: Heterogeneously Resistant Elastic-Brittle Solids under Multi-Axial Stress: Fundamental Postulates and Bounding Theorems, J. Acta Mechanica, vol. 226 (6), pp. 2077-2087 , doi: 10.1007/s00707-015-1299-1 (2015).

[9] Baratta, A., Corbi, I., Corbi, O.: Analytical Formulation of Generalized Incremental Theorems for 2D No-Tension Solids, J. Acta Mechanica, Vol. 226 (9), pp. 2849-2859, doi: 10.1007/s00707-015-1350-2 (2015).

[10] Baratta, A., Corbi I., Corbi, O.: Stability of evolutionary brittle-tension $2 \mathrm{D}$ solids with heterogeneous resistance, J. Computers and Structures, doi: 10.1016/j.compstruc.2015.10.004 (2015).

[11] Baratta, A., Corbi, O.: Contribution of the fill to the static behaviour of arched masonry structures: Theoretical formulation, J.Acta Mechanica, vol.225 (1), pp. 53 - 66, doi: 10.1007/s00707-013-0935-x (2014).

[12] Baratta, A., Corbi, I., Corbi, O. :Bounds on the Elastic Brittle solution in bodies reinforced with FRP/FRCM composite provisions, J. Composites Part B: Engineering, vol. 68, pp. 230-236, doi: 10.1016/j.compositesb.2014.07.027 (2015)

[13] Baratta, A., Corbi, O.: Closed-form solutions for FRP strengthening of masonry vaults, J. Computers and Structures, vol. 147, pp. 244-249, doi:10.1016/j.compstruc.2014.09.007 (2015).

[14] Baratta, A., Corbi, O.: An Approach to Masonry Structural Analysis by the No- Tension Assumption-Part I: Material Modeling, Theoretical Setup, and Closed Form Solutions. Applied Mechanics Reviews, ASME International. Appl. Mech. Rev., July 2010, Vol.63, 4, pp.040802-1/17. ISSN 0003-6900, DOI:10.1115/1.4002790 (2010).

[15] Baratta, A., Corbi, O.: An Approach to Masonry Structural Analysis by the No- Tension Assumption-Part II: Load Singularities, Numerical Implementation and Applications. Journal Applied Mechanics Reviews, vol.63(4), pp.040803-1/21, ISSN 0003- 6900, DOI: 10.1115/1.4002791, (2010).

[16] Baratta, A., Corbi, O.: On the statics of No-Tension masonry-like vaults and shells: Solution domains, operative treatment and numerical validation, Annals of Solid and Structural Mechanics, vol.2(2-4), pp.107-122, ISSN 1867-6936, DOI: 10.1007/s12356-011-0022-8 (2011).

[17] Baratta, A., Corbi, O.: Relationships of L.A. Theorems for NRT Structures by Means of Duality. Intern. Journal of Theoretical and Applied Fracture Mechanics, Elsevier Science, vol. 44, pp. 261-274. ISSN0167-8442 DOI: 10.1016/j.tafmec.2005.09.008 (2005).

[18] Baratta, A., Corbi, O.: On the equilibrium and admissibility coupling in NT vaults of general shape. Int J Solids and Structures, Vol. 47, 17, pp.2276-2284. ISSN: 0020-7683. DOI: 10.1016/j.ijsolstr.2010.02.024 (2010).

[19] Baratta, A., Corbi, O.: Duality in non-linear programming for limit analysis of NRT bodies, Structural Engineering and Mechanics, An International Journal, Technopress. vol. 26(1), pp.15-30, 2007. ISSN: 1225-4568 (2007).

[20] Baratta, A., Corbi, I.: Spatial foundation structures over no-tension soil. International Journal for Numerical and Analytical Methods in Geomechanics, vol. 29, pp. 1363-1386, Wiley Ed. ISSN: 03639061, DOI: 10.1002/nag.464 (2005).

[21] Baratta, A., Corbi, I.: Plane of Elastic Non-Resisting Tension Material under Foundation Structures. International Journal for Numerical and Analytical Methods in Geomechanics, vol. 28, pp. 531-542, J. Wiley \& Sons Ltd. ISSN 0363-9061, DOI: 10.1002/nag.349 (2004).

[22] Baratta, A., Corbi, I.: On the Statics of Masonry Helical Staircases, in B.H.V.Topping, Y. Tsompanakis, (Editors), Proceedings of the Thirteenth International Conference on Civil, Structural and Environmental Engineering Computing, Civil-Comp Press, Stirlingshire, UK, Crete; 6 -9 September 2011, Paper 59, 16p, ISBN: 978-190508845-4, DOI: 10.4203/ccp.96.59 (2011).

[23] Baratta, A., Corbi, I.: Equilibrium models for helicoidal laterally supported staircases, Journal of Computers and Structures, ISSN: 00457949, DOI: 10.1016/j.compstruc.2012.11.007 (2013).

[24] Baratta, A., Corbi, I.: Statics and Equilibrium Paths of Masonry Stairs, Open Construction and Building Technology Journal, Vol.6, pp.368372, ISSN: 1874-8368, DOI: 10.2174/1874836801206010368 (2012). 
[25] Baratta, A., Corbi, I., Coppari, S.: A method for the evaluation of the seismic vulnerability of fortified structures, Final Conference on COST Action C26: Urban Habitat Constructions under Catastrophic Events;Naples;16-18 September 2010; pp. 547-552, ISBN: 978041560685-1 (2010).

[26] Baratta, A., Corbi, I., Corbi, O., Rinaldis, D.: Experimental survey on seismic response of masonry models, Proceedings of the 6th International Conference on Structural Analysis of Historic Constructions: Preserving Safety and Significance, SAHC08, Bath;2 -4 July 2008; vol.8, pp.799-807, ISBN 0415468728;978-041546872-5 (2008).

[27] Baratta, A., Corbi, O.: An approach to the positioning of FRP provisions in vaulted masonry structures, Composites Part B: Engineering, doi.org/10.1016/j.compositesb.2013.04.043, (2013).

[28] Baratta, A., Corbi O.: Stress analysis of masonry vaults and static efficacy of FRP repairs, Int. Journal of Solids and Structures , vol.44(24), pp. 8028-8056, ISSN: 0020-7683., DOI: 10.1016/j.ijsolstr.2007.05.024 (2007).

[29] Baratta , A., Corbi, O.: Analysis of the dynamics of rigid blocks using the theory of distributions, Advances in engineering Software, vol.44(1), pp.15-25, ISSN: 09659978, DOI: 10.1016/j.advengsoft.2011.07.008 (2012).

[30] Baratta, A., Corbi, I., Corbi O.: Towards a Seismic Worst Scenario Approach for Rocking Systems. Analytical and Experimental Set Up for Dynamic Response, Journal Acta Mechanica, vol. 224 (4) , pp 691-705, ISSN: 0001-5970, DOI:10.1007/s00707-012-0787-9 (2013).

[31] Corbi, I.: FRP reinforcement of masonry panels by means of c-fiber strips, Journal Composites Part B, vol.47, pp. 348-356, ISSN: 13598368, DOI: 10.1016/j.compositesb.2012.11.005 (2013).

[32] Corbi, I.: FRP Composites Retrofitting for Protection of Monumental and Ancient Constructions, Open Construction and Building Technology Journal, vol.6, pp.361-367, ISSN: 1874-8368, DOI: $10.2174 / 1874836801206010361$ (2012). 